\title{
ANALYSES ON FRICTION STIR BASED TECHNIQUES TO JOIN LIGHTWEIGHT ALLOYS TO THERMOPLASTIC MATRIX PARTS
}

\section{F. GAGLIARDI 1 , G. SERRATORE ${ }^{1}$, R. IBANEZ ${ }^{2}$, E. CUETO ${ }^{3}$, L. FILICE ${ }^{1}$ AND F. CHINESTA ${ }^{2}$}

\author{
1DIMEG - University of Calabria \\ P. Bucci 45/C, Rende (Cs) 87036 \\ \{francesco.gagliardi, giuseppe.serratore, luigino.filice\}@unical.it \\ ${ }^{2}$ ESI Group Chair @ PIMM, Arts et Métiers ParisTech \\ 151 Boulevard de l'Hôpital, F-75013 Paris, France. \\ \{ruben.ibanez-pinillo, francisco.CHINESTA\}@ensam.eu \\ ${ }^{3}$ Department of Mechanical Engineering - University of Zaragoza \\ Maria de Luna, Zaragoza, Spain 50018 \\ ecueto@unizar.es
}

Key words: Mechanical Fastening, Dissimilar materials, Friction Stir Techniques, Machine Learning, Advanced regression, Data-Driven Techniques.

\begin{abstract}
Nowadays, the manufacturing research efforts have to be conceived in such a way that the product performance criteria are achieved in a lightweighting design concept. Taking these extensions to their extreme, the material properties and the manufacturing solutions have to be considered together in a revolutionary body concept, which should result in an ideal sight to the use of the most performing material in the right place depending on the product requirements. Polymer matrix composites (PMCs) belong to this new material category. The development of joining techniques available to connect PMCs and lightweight alloys has been considered as a key enabling solution in making innovative and sustainable products. The goal of obtaining high joint efficiency must face two main problems, i.e. to deal with the polymeric matrices to get mechanical, physical and chemical compatibilities and to attain or preserve the integrity of reinforcements across the joints customizing the fiber distribution in the joining area.

The understanding of current and emerging joining technologies, e.g. the friction stir based techniques, with an optimization of the process parameters needs performant numerical tools to be employed, efficiently. In the work herein proposed, a polymeric base plate was joined to an aluminum alloy part simulating the friction lap joint sequences. Numerical tests have been set by a commercial FE code (DEFORM 2D ${ }^{\mathrm{TM}}$ ) and a DoE, generated using hypercube sampling, was defined to perform a sensitivity analysis of specific investigated variables on some process outputs. A further objective is to create transfer functions involving the input and output quantities of interest. Particularly, the sparse Proper Generalized Decomposition (sPGD) is the implemented numerical algorithm that making use of two ingredients, the separation of
\end{abstract}


variables together with a collocation procedure, allows achieving a prediction tool usable in improving the process performance.

\section{INTRODUCTION}

Aluminum alloys and thermoplastic materials are widely used today to achieve lightweight concept design, for example in the automotive industries for reducing vehicle weights. A challenge is the development of joining techniques available to connect these materials through the optimization of innovative and sustainable joints.

This goal is not easy to reach if materials with dissimilar properties, such as PMCs and metals, need to be connected. Specifically, when an Aluminum alloy is joined with a thermoplastic material two issues arise, i.e. to deal with the polymeric matrices to get mechanical, physical and chemical compatibilities and to attain or preserve the integrity of reinforcements across the joints customizing the fiber distribution in the joining area. The understanding of current and emerging joining technologies according to the mechanisms of joint formation is, therefore, a key issue in boosting the manufacturing of composites. Among the mechanical fastening solutions, the friction stir based techniques have been developing in different variants [1,2]. Friction Spot Joining (FSpJ) represents one of the most promising solidphase joining techniques. FSpJ is an innovative technique patented by Helmholtz-Zentrum Geesthacht in Germany [3] for producing thin-sheet metal-polymer joints. The process is based on the frietion spot weic

The spot joints are called pin and sleeve,

ensure contact between rotational speed, which two process parameters th rding technology used to
xecuted through a non-c
which are mounted co
the parts to be eonnec
allows heating the join
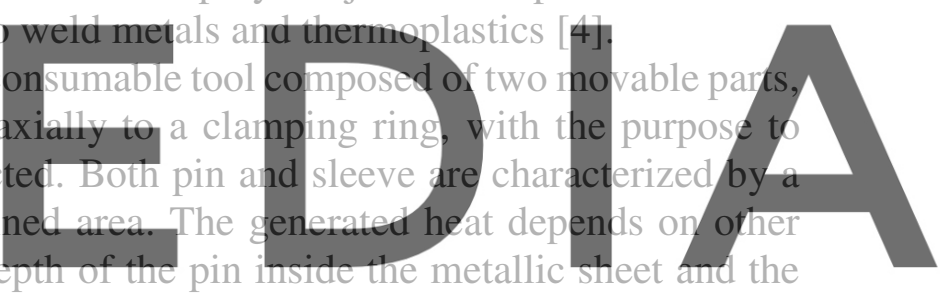
joining time, whose phases are schematized in Fig. 1.

\section{Register for free at https//www.scip}
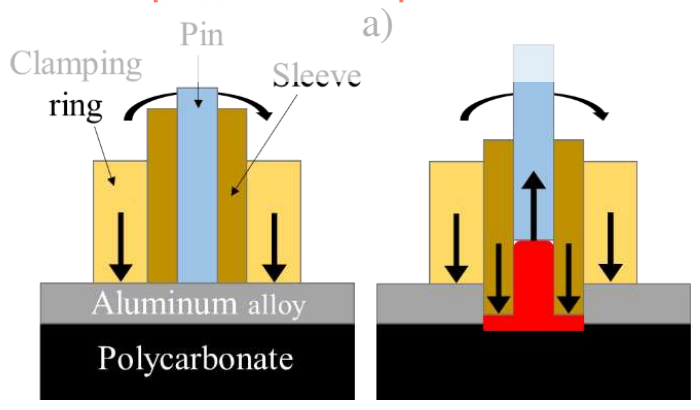

b)

c)
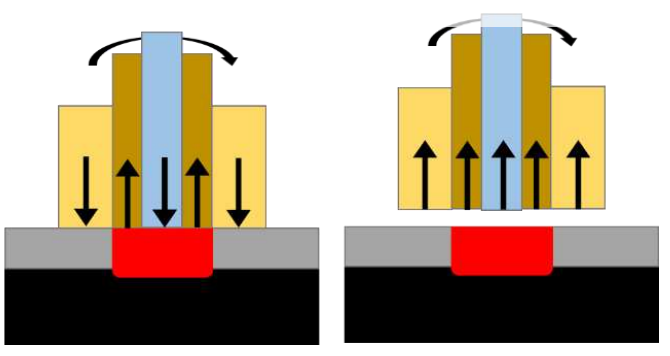

Figure 1: Schematic illustration of the Friction Spot Joining Process. The Sleeve plunging softens the Aluminum alloy (a); spot refilling (b) and joint consolidation (c).

Since this is an innovative and complex joining solution, several researches have been carried out from an experimental and numerical point of view $[5,6]$. Complex dynamics have to be considered, such as a material stirring, high deformation, heat flow, combination of material with different thermal and material flow properties, etc. The numerical models available in literature adaptable to the FSjP refer to the friction spot welding process for joining 
materials [7-11]. The main problem is the mesh distortion owing to the stirring effect of the tool rotation that is computationally expensive to solve and that could result in a premature simulation failure. Therefore, herein, the research has been focalized on setting of a simple but efficient 2D axisymmetric numerical model, which can be used to evaluate specific process outputs, which go to affect the behavior of the resulting joints. Furthermore, a statistical experimental plan was defined to analyze the influence of some identified variables on specific process outputs and an advanced regression technique was employed to predict the process answer at different working conditions.

\section{METHODOLOGY}

Two aluminium alloys, characterized by different mechanical properties, were joined individually to a polycarbonate plate. This section outlines a description of the adopted methodology. Specifically, the finite element model developed for the FSpJ, the Design of experiment (DoE) planning and the sparse Proper Generalized Decomposition (sPGD) technique are described.

\subsection{Model description}

The starting point is the development of a performant numerical tool suitable for the analysis and prediction of the FSpJ process, efficiently. To do this, the "Torsion" mode in the geometry section of DEFORM 2D ${ }^{\mathrm{TM}}$ was employed in order to reproduce the heat flow caused by the

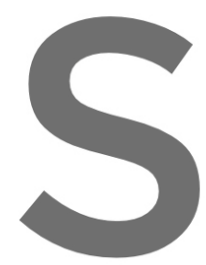
friction interaction, without excessively indreasing the computational effort. The main assumption of this model is to neglect the material stirring that could be sinulated only with a 3D approach.

The present mode representing the tool polycarbonate 2.17 mm-thick, in accordance with ASTM D3528 for the double lap shear (DLS)

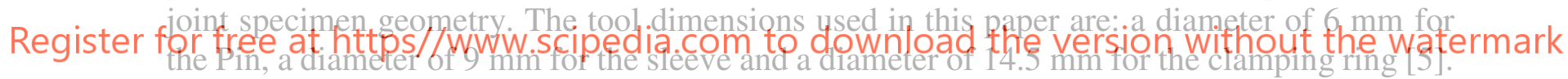
Initially, the number of elements is approximatively around 2500. Fig. 2 shows the adopted 2D axisymmetric finite element model.

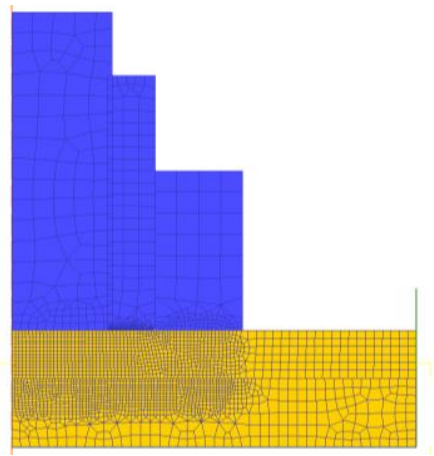

Figure 2: 2D Axisymmetric finite element model for the FSpJ process simulation

A coulomb friction coefficient of 0.5 was set between the aluminum and the polycarbonate 
sheet while a shear coefficient of 0.5 was considered among the other surfaces[12]. Finally, a $0.2[13] \mathrm{N} / \mathrm{mm} / \mathrm{s} /{ }^{\circ} \mathrm{C}$ heat transfer coefficient was set between the aluminum and the polycarbonate. The constitutive material models of the aluminum alloys, i.e., the AA 1050 and AA 2024 were expressed by Johnson-Cook's model [14], which considers the effects of strain hardening, thermal softening, and strain rate sensitivity, respectively. Table 1 provides the Johnson-Cook parameters for both materials. The thermal and elastic properties were considered as temperature-dependent in all simulations.

Table 1: Johnson-Cook plasticity model constant for AA 1050 [15] and AA 2024 [16]

\begin{tabular}{cccccccc}
\hline Material & $\mathrm{A}[\mathrm{MPa}]$ & $\mathrm{B}[\mathrm{MPa}]$ & $\mathrm{C}$ & $\mathrm{n}$ & $\mathrm{m}$ & $\mathrm{T}_{\text {room }}\left[{ }^{\circ} \mathrm{C}\right]$ & $\mathrm{T}_{\text {melt }}\left[{ }^{\circ} \mathrm{C}\right]$ \\
\hline AA 1050 & 110 & 150 & 0.01 & 0.4 & 1 & 20 & 645 \\
\hline AA 2024 & 352 & 440 & 0.0083 & 0.42 & 1 & 20 & 640 \\
\hline
\end{tabular}

Regarding the polycarbonate, the constitutive material model was expressed by the DSGZ [17], a viscoplastic phenomenological model developed for glassy or semi-crystalline polymers. This model considers the effect of the strain, strain rate, temperature, softening and hardening. The eight coefficients used are listed in Table 2.

Table 2: Material coefficent for polycarbonate [17]

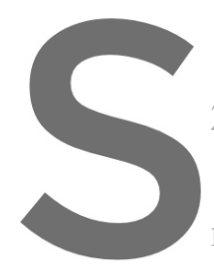

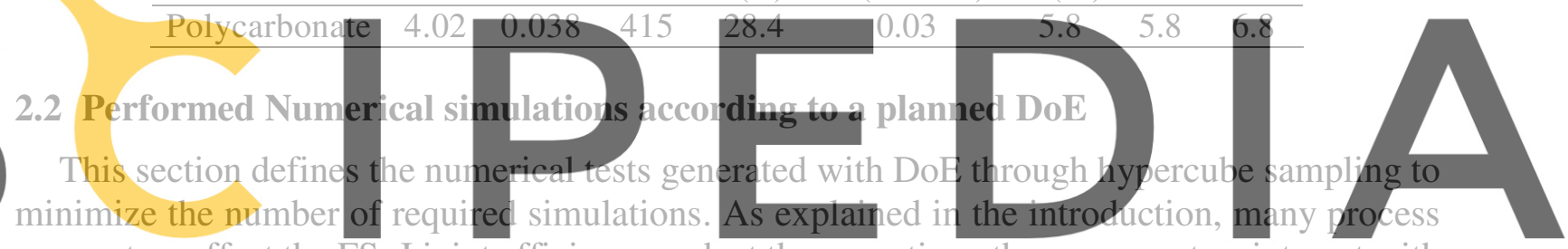
parameters affect the FSpJ joint efficiency and, at the same time, these parameters interact with Register for free at haking difficult to weight each influence ph the entire process wherefore a DoE based on Latin Hypercube sampling, was employed investigating four process parameters, 1.e. rotational speed, plunge depth, joining time and type of aluminum alloy, as reported in Table 3. For the sake of clarity, Fig. 3 shows the phases simulated with the FE model, according to Fig.1a and Fig.1b.

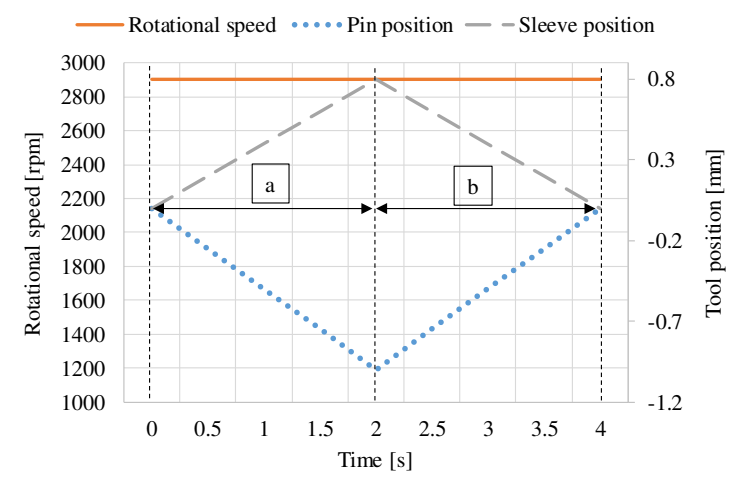

Figure 3: Variation monitoring diagram of the "a" and "b" FSpJ process phases considered in this work. 
F. Gagliardi, G. Serratore, R. Ibanez, E.Cueto, L. Filice and F. Chinesta

Table 3: FSpJ process parameters and their respective levels (min, max and step)

\begin{tabular}{cccccc}
\hline Factors & Symbol & Unit & Min & Max & Step \\
\hline Rotational speed & RS & rpm & 1000 & 3000 & 100 \\
\hline Plunge depth & PD & mm & 0.5 & 1 & 0.1 \\
\hline Joining time & JT & s & 4 & 8 & 0.5 \\
\hline Material & - & - & AA 1050 & AA 2024 & - \\
\hline
\end{tabular}

Additionally, the DoE was generated considering a total of 30 simulations, which results in 30 joining conditions as reported in Table 4, where the analyzed ranges can be detected.

Table 4: DoE matrix listing the 30 joining conditions

\begin{tabular}{ccccc}
\hline \multirow{2}{*}{ Joining condition } & \multicolumn{4}{c}{ Factors } \\
\cline { 2 - 5 } & RS (rpm) & PD (mm) & JT (s) & Material \\
\hline 1 & 2000 & 0.7 & 6 & AA 1050 \\
\hline 2 & 2800 & 0.7 & 4.5 & AA 2024 \\
\hline 3 & 1700 & 1 & 6 & AA 1050 \\
\hline 4 & 2100 & 0.6 & 5 & AA 2024 \\
\hline 5 & 1900 & 1 & 7.5 & AA 1050 \\
\hline 6 & 1400 & 0.6 & 8 & AA 2024 \\
\hline 7 & 2200 & 0.8 & 8 & AA 2024 \\
\hline 8 & 1500 & 0.9 & 7 & AA 1050 \\
\hline 9 & 1100 & 0.6 & 6 & AA 2024 \\
\hline 10 & 1000 & 0.5 & 5 & AA 1050 \\
\hline 11 & 2500 & 0.6 & 6 & AA 1050 \\
\hline 12 & 3000 & 0.5 & 7 & AA 1050 \\
\hline 13 & 2600 & 0.6 & 7.5 & AA 2024
\end{tabular}

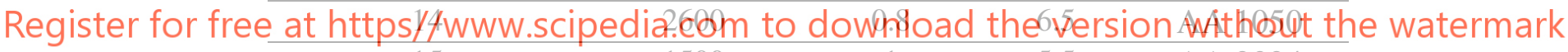

\begin{tabular}{ccccc}
\hline 15 & 1500 & 1 & 5.5 & AA 2024 \\
\hline 16 & 2400 & 0.9 & 5 & AA 2024 \\
\hline 17 & 2800 & 0.6 & 7 & AA 2024 \\
\hline 18 & 1600 & 0.9 & 5.5 & AA 1050 \\
\hline 19 & 1200 & 0.7 & 5 & AA 2024 \\
\hline 20 & 2300 & 0.8 & 4 & AA 1050 \\
\hline 21 & 1500 & 0.7 & 4.5 & AA 1050 \\
\hline 22 & 1200 & 0.9 & 6.5 & AA 2024 \\
\hline 23 & 1800 & 0.7 & 4.5 & AA 1050 \\
\hline 24 & 2700 & 0.9 & 5 & AA 2024 \\
\hline 25 & 2200 & 0.7 & 7.5 & AA 1050 \\
\hline 26 & 2400 & 0.9 & 7 & AA 2024 \\
\hline 27 & 1700 & 0.8 & 6.5 & AA 1050 \\
\hline 28 & 2900 & 0.8 & 5.5 & AA 1050 \\
\hline 29 & 1300 & 0.8 & 4 & AA 2024 \\
\hline 30 & 2000 & 0.5 & 6.5 & AA 2024 \\
\hline & & & & \\
\hline
\end{tabular}




\subsection{Sparse proper generalized decomposition technique}

The sparse Proper Generalized Decomposition (sPGD) technique aims to capture an objective function by means of the separation of variables as shown in eq. 1 .

$$
\boldsymbol{f}\left(p_{1,}, p_{2, \ldots}, p_{n}\right) \approx \mathbf{a}\left(p_{1,}, p_{2, \ldots}, p_{n}\right)=\sum_{m=1}^{M} \boldsymbol{u}^{m} g_{1}^{m}\left(p_{1}\right) g_{2}^{m}\left(p_{2}\right) \ldots g_{n}^{m}\left(p_{n}\right)
$$

where $\mathrm{M}$ is the number of enrichments (a.k.a. low-rank approximations) in the approximation and $\mathrm{n}$ is the number of dimensions in the parametric space.

Let's assume that the output function is known at several points inside the parametric space as shown in eq. 2 .

$$
f\left(p^{s}\right)=f_{s} ; \quad s=1, \ldots, S
$$

The sPGD solution is obtained by minimizing the following functional:

$$
\sum_{S=1}^{S} a_{S}\left(a_{S}-f_{S}\right)=0
$$

More in detail, a greedy procedure, where the previous knowns are fixed when looking at the new enrichment, plus an altered direction scheme are in charge of controlling the approximation.

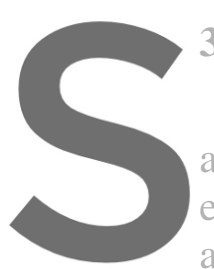

\section{RESULTS AND DISCUSSION}

This section presents

answers at their variatio

efficiency was evaluate
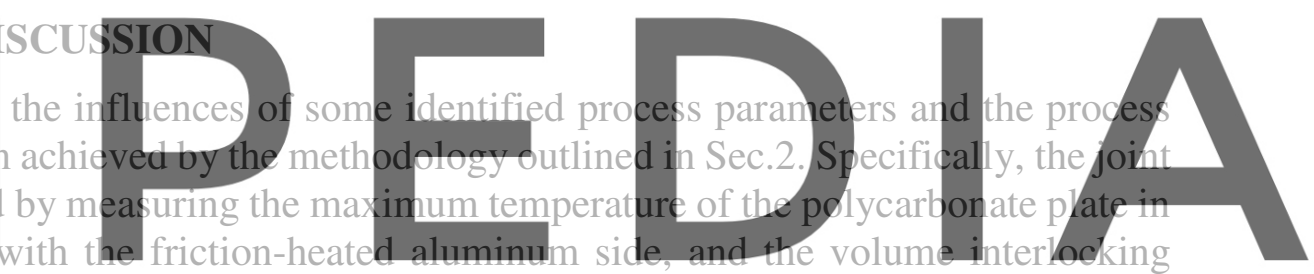

between these two materials. The choice of these outputs is related to thermal deterioration

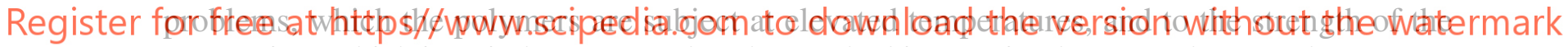
connection, which is strictly connected to the reached interaction between the two plates.

\subsection{FEM results}

In Fig. 4, there are images showing the typical temperature distribution, as a result of the 2D proposed FE model, at the end of phase "a" and phase "b" highlighted in Fig. 3.

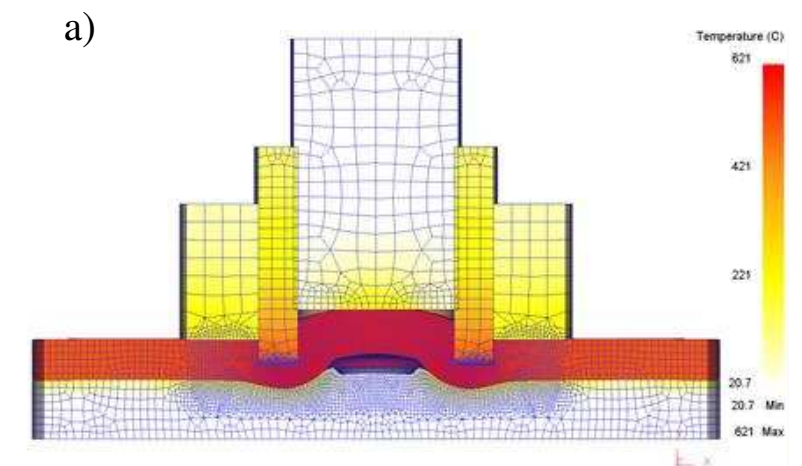

b)

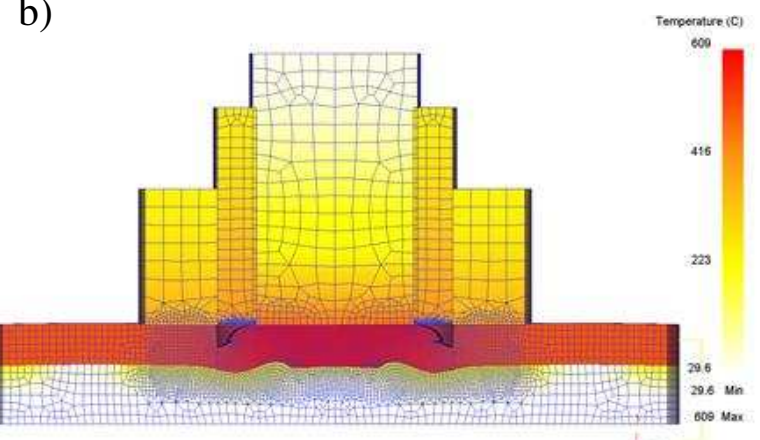

Figure 4: Typical result for the FSjP process simulation, at the end of the phase "a" (a) and "b" (b) 
The maximum temperature is located on the Aluminum plate in the area strictly connected to the rotating rigid tool. Herein, the metal is strongly stirred up to reach the melting temperature. The fluid material is first gathered below the pin (Fig. 4a) and, subsequently, pushed to the plastic plate resulting in a mechanical interlocking between the surfaces of the two parts (Fig. 4b). The joint performance is further consolidated by micromechanical adhesion, which is also function of the reached temperatures coupled to the generated contact pressures.

According to what above said, the selected outputs were: the maximum temperature of the peak and of the valley, which refer both to the polycarbonate sheet, and the interlocking area calculated as highlighted in Fig.5.

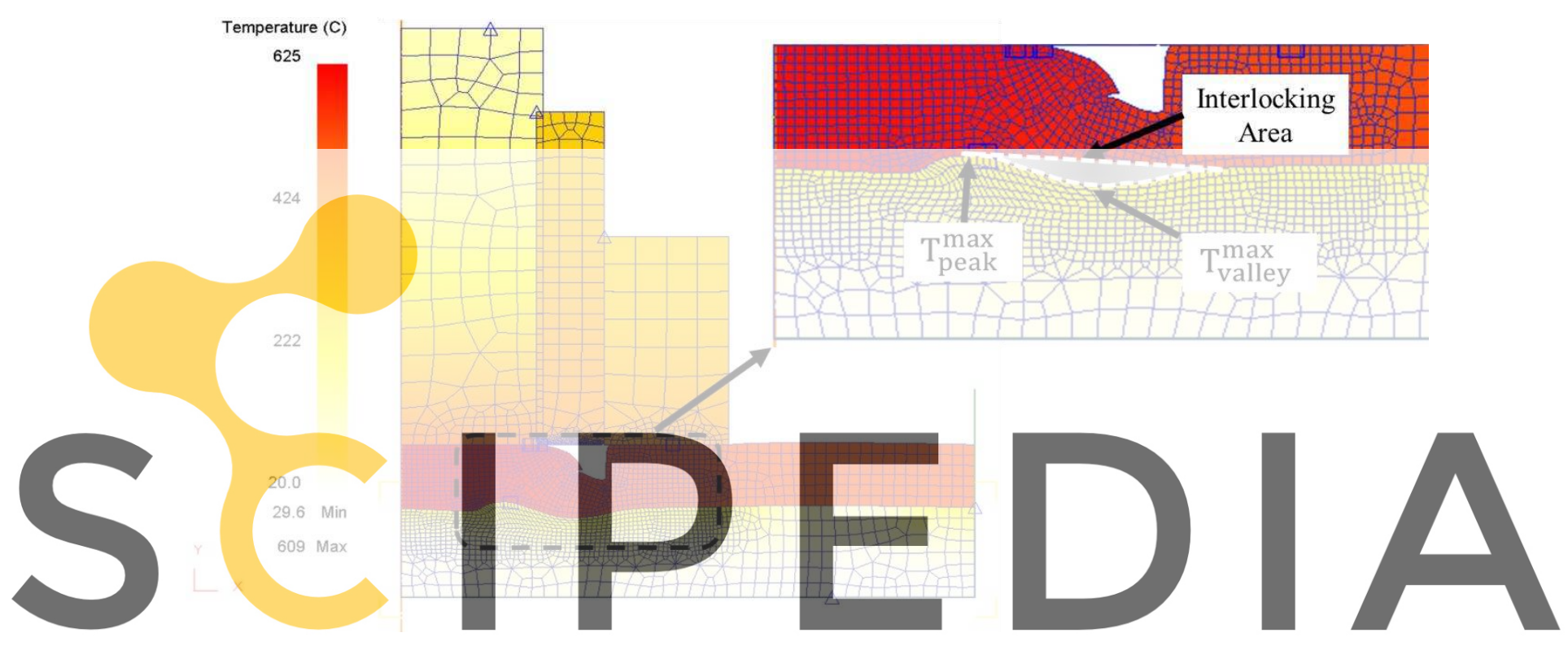

Figure 5: The selected results: the maximum temperature of the peak, the maximum temperature of the valley Register for free at https//www.scipedia.coling itorddowndoad the version without the watermark

For the joining conditions reported in Table 4, the obtained minimum and maximum values extracted by the conducted FE simulation are reported in Table 5 for the different tests.

Table 5: Range of the results obtained by the FE simulations

\begin{tabular}{ccccc}
\hline Factors & Symbol & Unit & Min & Max \\
\hline maximum temperature of the peak & $T_{\text {peak }}^{\max }$ & ${ }^{\circ} \mathrm{C}$ & 169 & 335 \\
\hline maximum temperature of the valley & $T_{\text {valley }}^{\text {max }}$ & ${ }^{\circ} \mathrm{C}$ & 146 & 304 \\
\hline Interlocking & $\mathrm{A}_{\text {interlock }}$ & $\mathrm{mm}^{2}$ & 25.44 & 4.59 \\
\hline
\end{tabular}

\subsection{Sensitivity analysis of the investigated process parameters}

The performed sensitivity analysis showed the individual influence of the selected joining parameters. The possible interactions among the highlighted variables were not taken into account. Fig. 6, 7 and 8 show respectively the influence of RS, JT and PD on $\boldsymbol{T}_{\text {valley }}^{\text {max }}$ and $\mathrm{A}_{\text {interlock. }}$ 

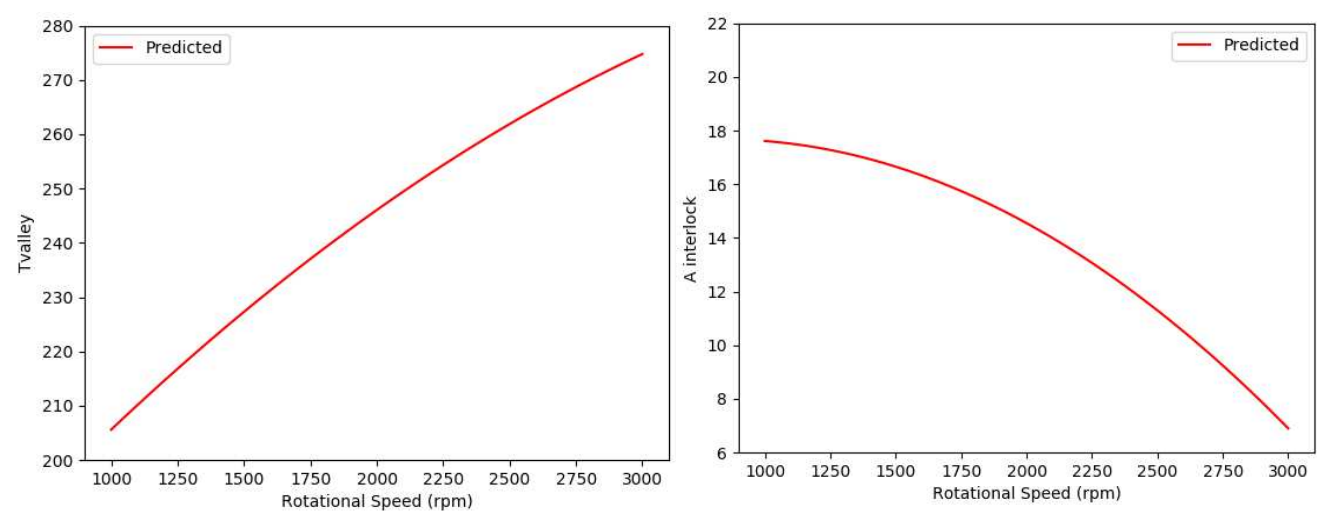

Figure 6: Influence of RS. Left, $T_{\text {valley }}^{\text {max }}$ for different RS. Right, $\mathrm{V}_{\text {interlock }}$ for different RS

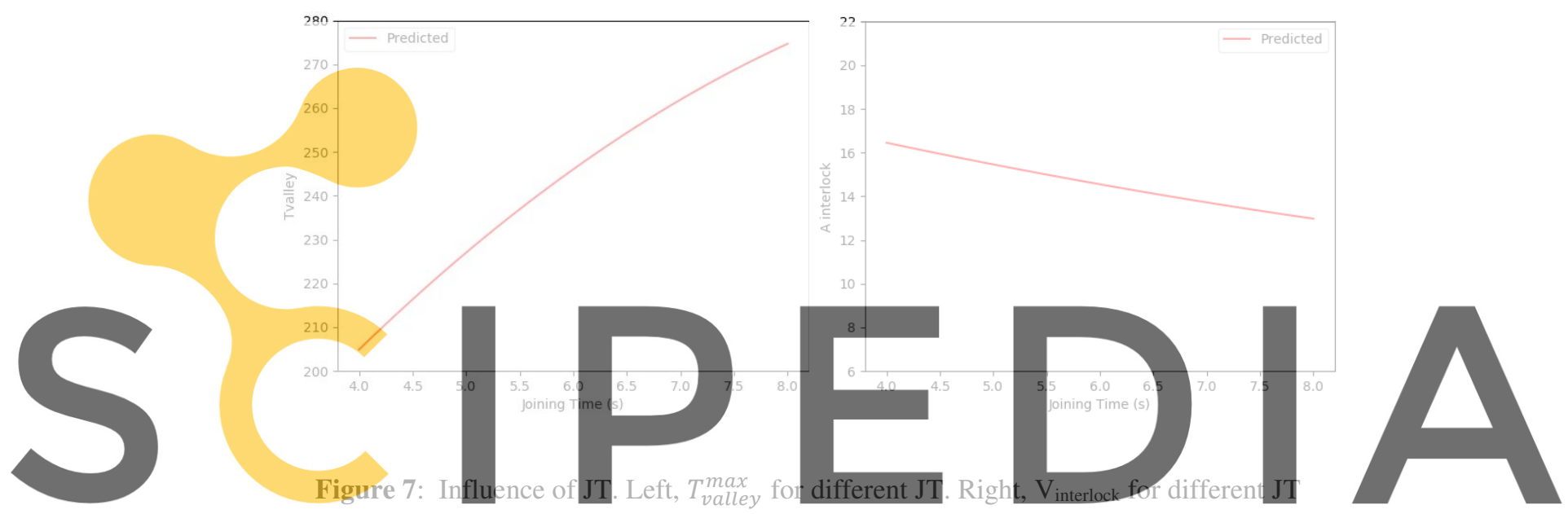

Register for free at https//www.scipedia.cometo download the version without the watermark
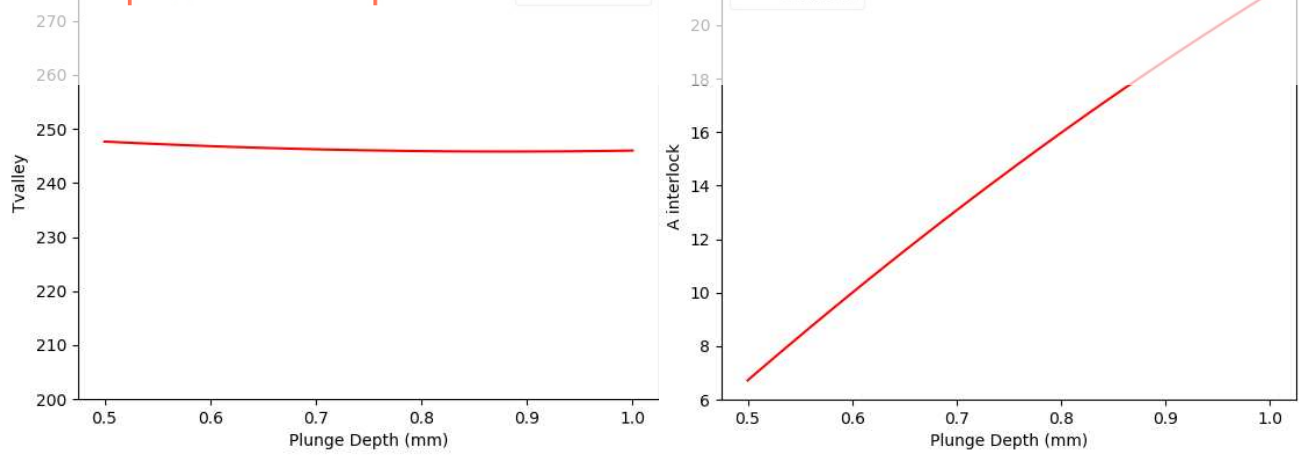

Figure 8: Influence of PD. Left, $T_{\text {valley }}^{\max }$ for different PD. Right, $\mathrm{V}_{\text {interlock }}$ for different PD

Before discussing the above reported figures, it deserves to be highlighted that:

1) the graphs of $\boldsymbol{T}_{\text {peak }}^{\text {max }}$ were not reported because resulted similar to $\boldsymbol{T}_{\text {valley }}^{\max }$.

2) the interlocking and the $\boldsymbol{T}_{\text {valley }}^{\text {max }}$ are, respectively, greater than about $50 \%$ and smaller than about $15 \%$ with the AA 1050 respect to the AA 2024. 
3) the current model is just a regression that matches the points that are established. Therefore, from these data it is possible to extract some important consideration.

Going deeply to the result analysis, first, from Fig. 6 and 7, it can be noted that there is a growth of $\boldsymbol{T}_{\text {valley }}^{\max }$ as RS and JT rise because of an increment of the generated friction heating, while, at the same time, there is a decrement in volume interlocking owing to a softening of the joined area during the pushing phase of the pin. The growth in volume interlocking vs JT after a minimum point can be, instead, ascribed to the melting of the polycarbonate as a result of the heat transmitted from the aluminum. Anyway, this evidence needs additional tests to be validated considering also the interdependency among the process variables. Finally, Fig. 8 illustrates an evident effect of PD in volume interlocking while this can be almost neglected for the trend of $\boldsymbol{T}_{\text {valley }}^{\text {max }}$. This results was justified because of the quantity of material moved that is strictly related the sleeve plunging inside the aluminum while the effect on the generated heat is less significant owing to the reduced increment of the contact surface in respect of the total contact area of the rigid tool.

\section{3 sPGD results}

For this particular problem the three scalar quantities of interest were taken into account, i.e., $T_{\text {peak }}^{\max }, T_{\text {valley }}^{\max }$ and $\mathrm{A}_{\text {interlock. }}$ All these three quantities depend on the four analyzed process parameters and, therefore, the problem was reformulated as finding:
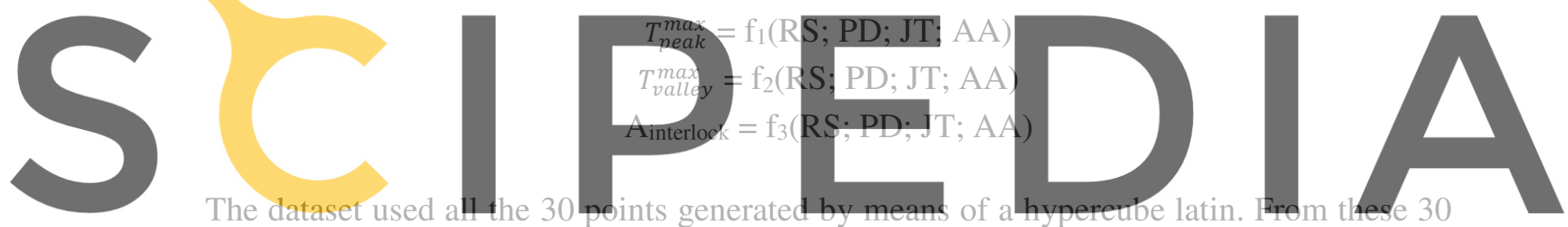

points, 24 points are kept in the training set whereas the other 6 are left outside to validate the

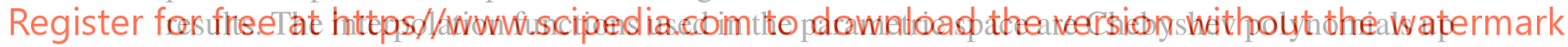

to linear interpolation, more polynomial order was tested but the results did not present better results. Fig. 9 shows the analysis involving $T_{\text {peak }}^{\max }$.
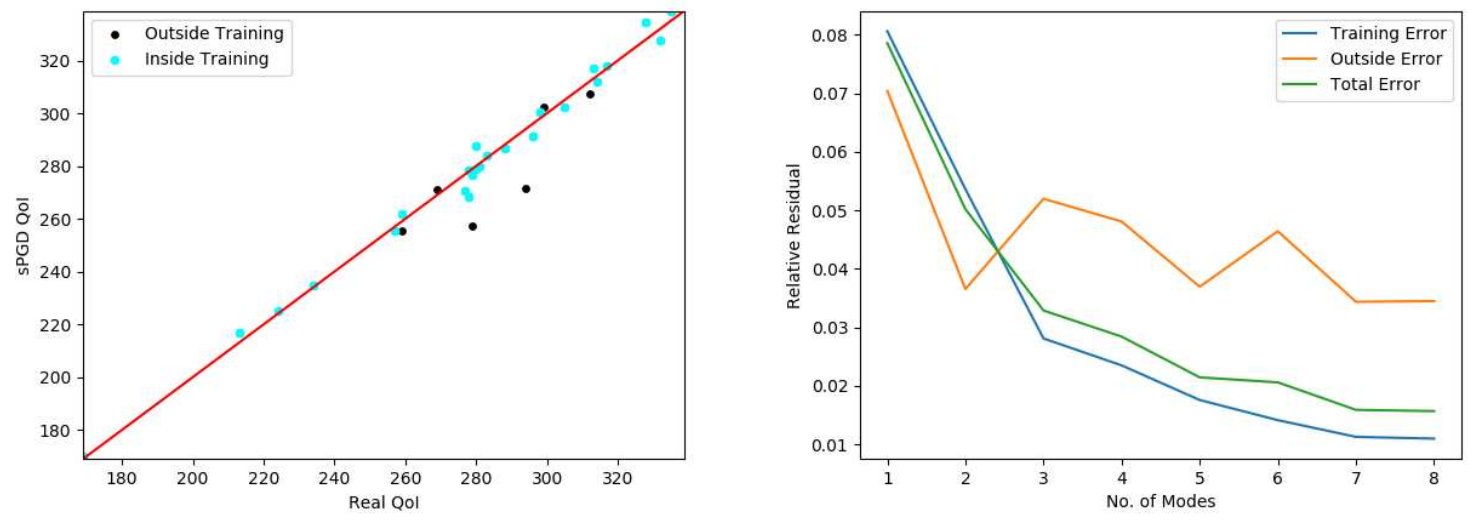

Figure 9: $T_{\text {peak }}^{\max }$. Left, real versus predicted. Right, convergence for different number of modes 
On the left side, it can be seen the real versus the predicted quantity of interest. There are two different colors, blue and black points, related to the training and outside training datasets, respectively. On the right-hand side, the relative residual of equation 3 is shown as the number of enrichments are increased (blue line). The residual can also be evaluated at the 6 points outside the training, generating the orange line. The results present a $1-2 \%$ relative error in the training, whereas $3-4 \%$ outside the training.
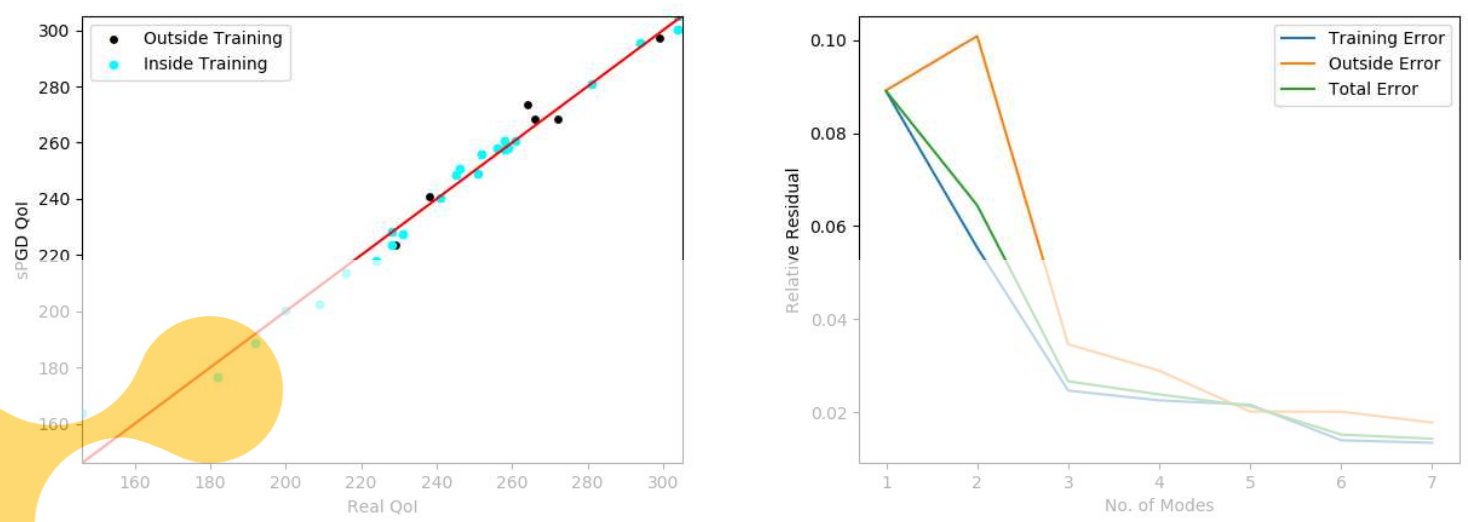

Figure 10: $T_{\text {valley. }}^{\max }$ Left, real versus predicted. Right, convergence for different number of modes
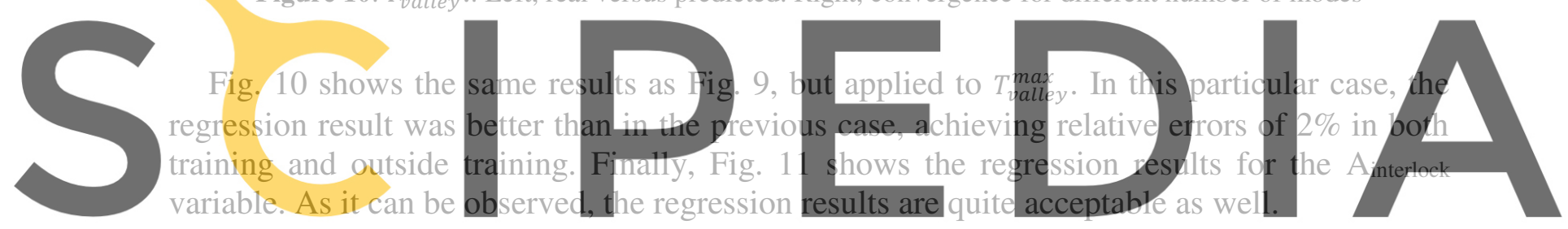

Register for free at https//www.scipedia.com to download the version without the watermark
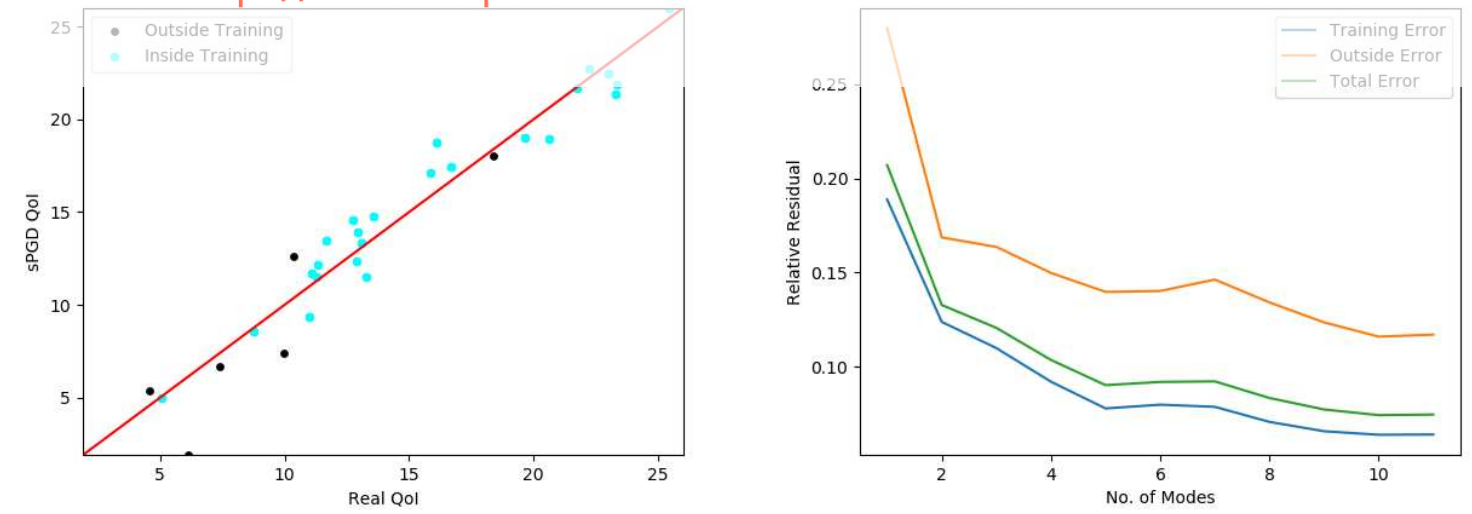

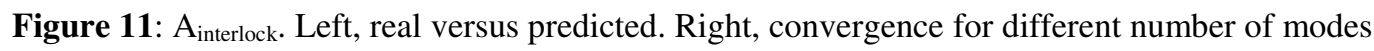

\section{CONCLUSIONS}

The Friction Spot Joining was investigated in joining dissimilar materials, i.e., lightweight alloys and plastics. Specifically, a 2D axisymmetric finite element model was set in order to be 
able to predict the performance of the obtained connections. Several simulation were ran changing the main process parameters according to a DoE planning. The monitored outputs were chosen taking into account the degradation problems that can occur on the surface of the joined plastic and the achieved mechanical interlocking, which affects the joint strength. Specifically, a sensitivity analysis allowed to understand the influence of each of the investigated process parameters on the highlighted outputs while the use of the sPGD technique allowed to define interpolation functions able to predict the quantities of interest, properly. The influences of the tool rotational speed, plunge depth, joining time and material properties of the process were evaluated, preliminary. Additional numerical tests, confirmed by experimental evidences, are required to validate what observed looking also at the relationship among the explored variables.

\section{REFERENCES}

[1] Goushegir, S.M., dos Santos J.F. and Amancio-Filho S.T. Friction Spot Joining of aluminum AA2024/carbon-fiber reinforced poly(phenylene sulfide) composite single lap joints: Microstructure and mechanical performance. Mater. Des. (2014) 54:196-206.

[2] Blaga, L., Dos Santos J.F., Bancila, R. and Amancio-Filho, S.T. Friction Riveting (FricRiveting) as a new joining technique in GFRP lightweight bridge construction. Constr. Build. Mater. (2015) 80 167-79.

[3] Amancio-Filho, S.T. and dos Santos, J.F. EP2329905B1 Method for joining metal and plastic workpieces. European Patent (2012)

[4] Schilling, C. and Dos Santos, J. Method and Device for Linking at Least Two Adjoining Work Pieces by Friction Welding (2001)

[5] Goushegir, S.M., dos Santos J.F. and Amancio-Filho S.T. Influence of process parameters on mechanical performance and bonding area of AA2024/carbon-fiber-reinforced poly(phenylene sulfide) friction spot single lap joints. Mater. Des. (2015) 83 431-42.

[6] Adibeig, M.R., Marami, G., Saeimi-Sadigh, M.A. and da Silva, L.F.M. Experimental and numerical study of polyethylene hybrid joints: Friction stir spot welded joints reinforced with adhesive. Int. J. Adhes. Adhes. (2020) 98102555.

[7] Yu, M., Li, W.Y., Li, J.L. and Chao, Y.J. Modelling of entire friction stir welding process by explicit finite element method. Mater. Sci. Tech. (2012) 28 812-817.

[8] Malik, V., Sanjeev, N.K., Hebbar, H.S. and Kailas, S.V. Investigations on the effect of various tool pin profiles in friction stir welding using finite element simulations. Proc. Eng. (2014) 97 1060-8.

[9] Ansari, M.A., Samanta, A., Behnagh, R.A. and Ding H An efficient coupled Eulerian-Lagrangian finite element model for friction stir processing. Int. J. Adv. Manuf. Technol. (2019) 101 1495-508

[10] Chen, K., Liu, X. and Ni, J. A review of friction stir-based processes for joining dissimilar materials Int. J. Adv. Manuf. Technol. (2019) 104 1709-1731.

[11] Chiumenti, M., Cervera, M., Agelet de Saracibar, C. and Dialami, N. Numerical modeling of friction stir welding processes Comput. Methods Appl. Mech. Eng. (2013) 254 353-369.

[12] Buffa, G., Hua, J., Shivpuri, R. and Fratini, L. A continuum based fem model for friction stir welding - Model development Mater. Sci. Eng. A (2006) 419 389-396.

[13] Fuller, J.J. and Marotta, E.E. Thermal Contact Conductance of Metal/Polymer Joints: An Analytical and Experimental Investigation. J. Thermophys. Heat Transf. (2001) 15 228-38.

[14] Johnson, G.R. and Cook, W.H. A constitutive model and data from metals subjected to large strains, high strain rates and high temperatures Proc. 7th \{I\}nt. \{S\}ymp. on $\{$ B\}allistics, \{T\}he $\{$ H\}ague, $\{N\}$ etherlands (1983).

[15] Eide, H.O.S. and Melby, E.A. Blast loaded aluminium plates Experiments and numerical 
simulations. Master Thesis (2013) 1-139.

[16] Asad, M., Girardin, F., Mabrouki, T. and Rigal, J.F. Dry cutting study of an aluminium alloy (A2024-T351): A numerical and experimental approach. Int. J. Mater. Form. (2008) 48 1187-1197.

[17] Duan, Y., Saigal, A., Greif, R. and Zimmerman, M.A. A uniform phenomenological constitutive model for glassy and semicrystalline polymers Polym. Eng. Sci. (2001) 41 1322-1328. 